\title{
Préhistoire Atlantique, fonctionnement et évolution des sociétés du Paléolithique au Néolithique
}

\section{Emmanuel Ghesquière}

\section{(2) OpenEdition Journals}

Édition électronique

URL : http://journals.openedition.org/rao/3195

DOI : $10.4000 /$ rao. 3195

ISBN : 978-2-7535-5014-8

ISSN : $1775-3732$

Éditeur

Presses universitaires de Rennes

\section{Édition imprimée}

Date de publication : 31 décembre 2015

ISBN : 978-2-7535-5012-4

ISSN : 0767-709X

\section{Référence électronique}

Emmanuel Ghesquière, «Préhistoire Atlantique, fonctionnement et évolution des sociétés du Paléolithique au Néolithique », Revue archéologique de l'Ouest [En ligne], 32 | 2015, mis en ligne le 28 avril 2016, consulté le 02 mars 2021. URL : http://journals.openedition.org/rao/3195 ; DOI : https:// doi.org/10.4000/rao.3195 
qui pourrait s'avérer fondamental pour la découverte d'amas coquilliers antérieurs à la fin du VII ${ }^{e}$ millénaire. Ce domaine tombé d'ailleurs depuis peu dans l'escarcelle de l'archéologie de sauvetage classique pourrait dans les prochaines années donner des résultats importants (éoliennes marines, hydroliennes) pour peu que des prescriptions de diagnostic soient établies.

Grégor revient ensuite sur le processus de néolithisation de la façade atlantique, que ce soit par le courant méditerranéen (via le NACA) ou par le courant septentrional (Rubané/BVSG). Cette intervention des premiers agriculteurs marque la fin de la lisibilité des peuples mésolithiques (avec un hiatus de 3 ou 4 siècles) même s'il reste encore quelques incertitudes sur une perduration au début du $V^{e}$ millénaire en milieu insulaire (Hoëdic), encore une fois avec toutes les réserves qu'impose l'effet réservoir sur les datations ${ }^{14} \mathrm{C}$ en domaine maritime. La reprise d'idées générales expliquant le remplacement des chasseurs-cueilleurs par les agriculteurs reprend les différentes hypothèses partagées ou discutées par les différents chercheurs : crise climatique de la fin du $\mathrm{VI}^{\mathrm{e}}$ millénaire, maladies épidémiques, guerre, moindre démographie, hypergénie... C'est potentiellement la conjugaison de ces différents facteurs qui parviendrait à expliquer ce remplacement, mais ils restent tous invisibles à la pratique archéologique. Par ailleurs, le développement du monumentalisme funéraire ou " cultuel » dans le Morbihan (tumulus, alignement de stèles) trahit une expansion démographique néolithique très rapide au début du $V^{e}$ millénaire, qui fait curieusement pendant à l'importance présumée des occupations mésolithiques dans le même secteur quelques siècles auparavant. Cette densité aussi bien mésolithique que néolithique témoigne à tout le moins d'une richesse alimentaire du littoral breton.

Emmanuel GHESQUiÈRE (Inrap, UMR 6566-CReAAH) 